\title{
A Commentary on Pop up Hospitality Ventures in the UK
}

\author{
By Peter Jones * \\ Daphne Comfort \\ David Hillier
}

Purpose -This commentary paper outlines the origins and nature of the pop up hospitality phenomenon, provides a range of illustrative examples of the variety and characteristics of pop up hospitality ventures within the UK and offers some reflections on the impact of pop up hospitality outlets and on the future of such ventures within the hospitality industry. Design/Methodology/Approach -The paper begins with a brief review of the pop up hospitality phenomenon and of experiential marketing and this is followed by an illustrative review of the range of pop up restaurants, bars and hotels within the UK. The information on for the paper is drawn from the corporate websites of pop up hospitality operators and agencies and on faceto-face discussions with hospitality pop up operators. Findings - The paper reveals that pop up hospitality ventures have been developed in a variety of formats and locations within the UK. A number of factors have driven the development of pop up hospitality ventures including providing entrepreneurs with relatively low cost opportunities to market test their ideas, skills and expertise and potentially to build their brand and provision of opportunities for customers to develop relationships with these entrepreneurs, with the food and drink they offer and with other customers often in an innovative environment. Many pop up ventures have actively embraced experiential marketing and as such, they can be seen to offer new approaches to marketing within the hospitality industry. Originality/Value - The paper provides an accessible review of the variety of pop up hospitality ventures within the UK and as such will interest professionals in the hospitality industry as well as academics and students interested in contemporary hospitality management.

Keywords: Pop up hospitality ventures, experiential retailing, market testing, customer relationships.

\section{Introduction}

The imperative to continually extend and enhance both the nature and the quality of the service experience makes the hospitality industry one of the most dynamic and innovative elements within the service sector of the economy. During the past decade this dynamism has been demonstrated, for example, in the tremendous growth in the size of cruise ships and the increasing sophistication of the ocean cruising experience (Jones et al., 2017) and in the

\footnotetext{
* Professor of Management, Business School, University of Gloucestershire, Cheltenham, UK.

* Research Administrator, Business School, University of Gloucestershire, Cheltenham, UK.

${ }^{\dagger}$ Emeritus Professor, Centre for Police Sciences, University of South Wales, Pontypridd, Wales, UK.
} 
ways in which innovative technologies and business models have revolutionised the hospitality industry (Bilgihan and Nejad, 2015). At the same time experiential marketing, namely a marketing strategy that directly engages customers, helps them to experience a brand and looks to create a closer bond between the consumer and the brand by immersing them in that experience in a memorable and an emotional way, has become a cornerstone of many recent advances in areas such as retailing, tourism and events marketing (Atwal and Williams, 2009). The continuing dynamism of the hospitality industry and the increasing emphasis on experiential marketing are epitomised by the growth of 'pop up' hospitality venues, events and experiences. In many ways as consumers look for new and innovative hospitality experiences, experiential marketing, with its emphasis on face-to-face customer engagement to connect with consumers and on creating relationships, might be seen as the fundamental driver for pop up hospitality venues. With this in mind this short commentary paper outlines the origins and nature of the pop up hospitality phenomena and sketches a brief introduction to experiential marketing, provides a range of illustrative examples of the variety and characteristics of pop up hospitality ventures within the UK and offers reflections on both the impact of pop up hospitality venues at a number of levels and on the future of such ventures within the hospitality industry.

\section{The Pop up Hospitality Phenomena and Experiential Marketing}

In general terms Barras (2016: 3) defines a pop up 'as any event that is temporary and involves people taking part as hosts and attendees.' Within the hospitality industry the pop up phenomena embraces restaurants, bars and hotels and encompasses a wide variety of offers and service experiences in a range of locations but the ephemerality or temporary nature of these establishment is their defining characteristic. The life span of pop up restaurants, bars and hotels' can range from just 24 hours, through a few days and weeks often with a seasonal or event focus, and in some cases up to a year. Typically, locations include vacant retail, warehouse and industrial spaces, roof top sites, boats, canal towpaths, bars and rooms in people's homes. The pop up phenomena per se is not new and Myrick (2016) claimed that 'originally come from the prohibition idea of speakeasies.' At one end of the spectrum fish and chip vans have been trading at rugby and soccer stadia within the UK for many years while at the other end Jim Haynes, an American born some time theatrical impresario, university lecturer and alternative cultural icon, claims to have been hosting Sunday lunch for up to 120 people in his Paris apartment for over thirty years (Haynes, 2016). That said Myrick (2016) suggested that 'the term "pop up restaurant" was practically non-existent prior to 2009.' However pop up hospitality has diversified and gained momentum within the past decade. In the restaurant sector within the US, for example, pop up dining events were identified as the fastest growing food and drink events with San 
Francisco, New York, Boston and Los Angeles being the major centres for such events.

A range of factors seem to be important in helping to explain the development and growing popularity of pop up hospitality. Within the restaurant sector, for example, pop up dining offers new young chefs and potential restaurateurs the opportunity to test their ideas, skills and expertise and potentially to build their brand. At the same time customers are attracted by the potentially new or possibly unique menus and dining experiences, which will generally include interaction with the chef and with other diners, and by the appeal of an unusual location. Such experiences can have an important multiplier effect in that 'pop up events can turn guests into powerful, vocal advocates for chefs and restaurants' (Eventbrite, 2015). The Internet and more specifically the growth in social media has also played a major role in marketing pop up restaurants and many pop up entrepreneurs have harnessed social media effectively and innovatively to promote their restaurants. Here using creative advertising strategies, encouraging customers to make fully paid up reservations using PayPal and harnessing viral marketing to facilitate the cheap, widespread and rapid dissemination of menus and events, for example, are also seen to have been vitally important in promoting the growth and success of pop up restaurants.

A number of financial factors have also driven the growth in the popularity of pop up restaurants. Many pop up restaurants are seen to have an innovative social cache and entrepreneurs can charge premium prices for what are often marketed as unique menus and dining experiences. Pop up restaurants do not require long-term financial investment and commitment and if they are not financially successful in one location they can be quickly closed and dismantled prior to establishment elsewhere. That said while ephemerality and portability certainly have attractions, pop up restaurants have to comply with a range of regulatory and legislative requirements, typically relating to leasing, licensing, health and safety, planning and secure the provision of power, water and waste disposal facilities which can all add to start-up and running costs. Relaxations in some regulations can facilitate the development of pop up enterprises. The UK Government, for example, introduced permitted development rights to allow for the temporary use of buildings classed for business, office, assembly, leisure, and other non-residential for retail use for up to two years (The Department for Communities and Local Government, 2013). These changes reduce both the delays and the costs associated with having to submit a planning application.

While novelty and variety of the experience are a characteristic feature of pop up hospitality, common characteristics, for example engagement and the development of a relationship with the operators and entrepreneurs, the opportunity in restaurants to discuss the menu and the sources of the ingredients with the chefs, and thus to form more personal connections with their food, with the chef, to enjoy new and enjoyable dining experiences with like-minded customers and to taste speciality beer brands in pop up pubs all strike a powerful chord with the concept of experiential marketing. Essentially 
experiential marketing looks to create and develop a closer relationship between a brand or service by providing the customer with a memorable and enjoyable experience. Atwal and Williams (2009: 342), for example, argued that experiential marketing is 'about taking the essence of a product and amplifying it into a set of tangible, physical and interactive experiences that reinforce the offer' and that it 'essentially describes marketing initiatives that give consumers in-depth, tangible experiences in order to provide them with sufficient information to make a purchase decision' and that 'it has evolved as a response to a perceived transition from a service economy to one personified by the experiences in which consumers participate.' Schmitt (1999: 53) draws the distinction between 'traditional marketing' which 'views consumers as rational decision-makers who care about functional features and benefits' whereas 'experiential marketers view consumers as rational and emotional human beings who are concerned with achieving pleasurable experiences.' However while Petkus (2004: 49) claimed that 'experiential marketing has become a cornerstone of recent advances in retailing, branding and events marketing' Yuan and Wu (2008: 387) argued 'although experience is recognized as a major benefit the hospitality and tourism industry offers, the use of experiential marketing in this industry is not well documented.'

\section{Method of Enquiry}

Anecdotal and observational evidence suggests that pop up hospitality ventures are becoming increasingly popular in the UK but the ephemeral nature of these ventures makes it difficult to obtain a detailed picture of the nature, scale and distribution of such operations. The term ephemeral is derived from the Greek word 'ephemeros' meaning 'lasting only for a day' but it is more widely used to refer to short lived or transient events and ephemerality can have both spatial and temporal dimensions and be seen through a variety of social and cultural lenses. Ephemerality is also seen as a characteristic of post modernity (Clammer, 2012) and more specifically in the current context as a postmodern trait within 'today's marketing and consumer environment' (Baker, 2003:18). More generally reporting and examining ephemeral events poses significant challenges for researchers and while some work has been published in detecting ephemeral events, for example, in the computing literature (Dutta et al., 2005) and in art (Potts, 2007) there is little guidance on approaching such challenges within the standard literature on research methods in business and management. However, Hine (2011: 3) suggested that 'the Internet can make previously ephemeral and hard to record aspects of daily life into researchable phenomena.' That said Hine (2011: 3) also warned that data obtained from the Internet may reflect proprietary algorithms which order specific search engines and which may lead to a biased portrayal of what is actually on the Internet.

While pop up venues are found in towns, cities and rural areas, and at a range of sporting and cultural events, throughout the UK, information on both their numbers and locations tends to be most readily publicly available on 
dedicated Internet websites. With this in mind rather than looking to provide a comprehensive national picture of the scale of pop up restaurants, pubs and hotels, the authors offer a number of illustrative examples, drawn principally from the larger cities where market potential is perceived to be greatest, to provide information on the current nature and variety of the pop up hospitality scene within the UK. More specifically the authors conducted an Internet search in January 2017, using Google as the search engine, using the key phrases 'pop up restaurants and bars' the city names 'London ', 'Birmingham', 'Cardiff' and 'Edinburgh.' This information was supplemented by information obtained, in January 2017, from the corporate websites of two companies, which specialise in supplying pop up bars and pop up hotels in free standing locations and on discussions held in July and December 2016 with pop up hospitality operators in two venues in Edinburgh. The authors recognise the limitations of this approach, not least in terms of the bias mentioned above but given the lack of existing research on pop up hospitality venues the authors believe that an examination of Internet websites is an appropriate choice for the current exploratory paper.

\section{Pop up Restaurants, Pubs and Hotels in the UK}

London, perhaps not surprisingly given its large number of people with high levels of disposal incomes, it's role as an all year round tourist destination and its image as an innovative urban centre, seems to stand out as the major centre for pop up hospitality within the UK. The 'London Pop-ups' website claims to detail all the pop up restaurants and bars within London (London Pop-ups, 2016) and produces a weekly newsletter which, on January $5^{\text {th }} 2017$, listed events from December $15^{\text {th }} 2016$ to January $1^{\text {st }} 2017$. The website includes a Google map which shows the location of some 50 pop up restaurants and bars in and around central London and provides information for each on menus, opening times and car parking facilities. Restaurants and bars included 'Mirey's Restaurant French Residency' at a licensed public house in Islington; 'Romy Gill's Indian Residency', also at a licensed public house in Marylebone; the ' 2 Fingers Lunchtime Fish Finger Sandwich Pop-up at the Canvas Cafe' off Brick Lane; 'The Pergola on the Roof' which included four restaurants on the roof of the car park at the former BBC Television Centre in Shepherd's Bush; and 'Rekorderligs Winter Pop-up Cider Lodge on the South Bank.' The website also included details of 'Quinto Quarto's Italian New Year's Eve Dinners' in Stoke Newington and 'Homeslice's New Year's Day Slice and Spritz Party' in Shoreditch both of which were open, as their title implies, for just one and two days respectively.

Mirey's Restaurant, a culinary collaboration established in 2016 between two chefs namely Gerard Mirey and Ko Ito, took over the kitchen at the Cuckoo from January $5^{\text {th }}$ 2017. The restaurant was open for four days a week offering both French and Japanese cuisine on Thursday and Friday evenings and brunch on Saturday and Sunday. The 2 Fingers' Lunchtime Fish Finger 
Sandwich Pop-up opened in Hanbury Street on January 5th 2017 and served the chef's signature sandwiches with handmade fish goujons as well as 'old skool' sandwiches made with Birds Eye brand fish fingers and crab and vegetarian options. Romy Gill, owner of Romy's Kitchen an Indian restaurant in Thornbury, Bristol returned to 'The Carousel' in Blandford Street, Marylebone between January $5^{\text {th }}$ and January $14^{\text {th }}$ for eight dinners. The four restaurants in the Pergola on the Roof, were 'Snaps and Rye' (Danish), 'Patty and Bun' (Burgers), 'Le Bab' (Gourmet Kebabs) and 'Gunpowder' (Indian). Rekorderlig opened its Scandinavian style cider lodge on Thursdays, Fridays, Saturdays and Sundays from November $11^{\text {th }} 2016$ to January $22^{\text {nd }} 2017$ as part of the South Bank Winter Festival and served a range of ciders, hot cocktails and Swedish food. The lodge featured classic Swedish furniture and traditional fire pits and customers can capture Swedish memories in an interactive photobooth. The Homeslice in Shoreditch offered one hour bookings from 12.00 until 23.00 on New Year's Day with unlimited pizza slices and drink for a set price while Quinto Quarto offered seven course Indian dinners on December $30^{\text {th }}$ and $31^{\text {st }}$ at the Green Room Café in Stoke Newington.

London also offers a variety of pop up bars and here again a number of dedicated websites provide details of themes and locations. The 'designmynight' website (designmynight, 2016), for example, includes 'Little Nan's Rio Bar' in the Rio Cinema in Dalston, which was open for three months from January $5^{\text {th }} 2017$ and 'Skye Halla', a rooftop Viking themed bar in Shoreditch which opened between 16.00 to 22.00 from October 2016 through to April 2017 and served hot and cold alcoholic drinks and offered customers the opportunity to participate in Viking life drawing and hair braiding workshops. The 'Barchick' website (Barchick, 2016) includes the 'Big Apple in Brixton', 'Pitch Black', and the 'Naked Pool Party. 'The Big Apple on a rooftop location in Pope's Road, Brixton which was open from $27^{\text {th }}$ October 2016 to January $1^{\text {st }} 2017$ included three bars and a nightclub underneath a canvas canopy and offered cocktails, street food, music and immersive theatre. Pitch Black in Shoreditch offers customers a 90-minute experience of champagne, sensory awakening cocktails, amuse bouches (single bite hors d'oeuvre) and wine tasting which takes place, as the pop up's name implies, in completer darkness. Guests at the Naked Pool Party, a fortnightly event running from 12.00 to 17.00 , could wear underwear or beachwear, or were encouraged to cover themselves up with waterproof body paint if they preferred to go naked, and were served with drinks by naked bar staff.

Birmingham also hosts a lively pop up hospitality scene. Here the 'designmynight' website (designmynight, 2015), for example, listed a number of pop up venues including 'Street Banquet', 'The Nowhere Bar', 'Amusement 13', 'Norjske' and 'Beermarket.' The Street Banquet in Digbeth, for example, offered food from a range of operators including 'Delizie Italiane', 'Pietanic', 'Spectacular Goat', 'The Butchers Social', 'Street Food Debut', 'The Flying Cows' and 'Victoria Creperie' and drinks included hand crafted gin and a selection of wines and real ales. The Nowhere Bar, for example, opened for just two nights in August 2014 on the second floor of a canal side warehouse in 
Digbeth while Norske, located above the Edgbaston Deli some two miles south of the city centre, opened over Christmas 2013 and served real ales, champagne and aquavit in a Scandinavian themed environment. The WalesOnline website (WalesOnline, 2015) lists a number of online hospitality venues in Cardiff, including the 'Hangfire Smoke House', 'Clwb Brecwast', 'Two Fingers Drinks' and the 'Drunken Sailor.' Clwb Brecwast, for example, was an early morning project at the 'Got Beef' restaurant on Whitchurch Road three miles from the city centre and it offered a range of cooked breakfast options.

Edinburgh hosts one of the world's largest annual cultural festival each summer and while this event provides opportunities for a wide range of pop up hospitality venues the city's image as Scotland's unofficial cultural capital seems to support a variety of pop up restaurants and bars throughout much of the year. In 2016, for example, the 'This is Edinburgh' website (This is Edinburgh, 2016) listed a number of pop up venues including 'One Square Pickering Gin Terrace', 'Dram and Smoke', the 'Edinburgh Gin Garden', 'Hopscotch', 'Brew Lab Takeovers', and 'Burger and Fringe.' The two entrepreneurs behind Dram and Smoke took over a floor in a former biscuit factory in Leith for the month covering the Edinburgh Festival. A range of dishes, including smoked ham hock, haggis terrine served with tattie (potato) scones, pearl barley risotto, braised beef brisket and rhubarb and custard. All dishes were served from an open kitchen, the majority of the produce was sourced from Scottish suppliers and included an array of locally foraged vegetables and herbs and the restaurant had a rotating nightly programme of live music performances. Brew Lab, a local independent coffee specialist, made over two of their premises in the city to 'Milk Money', a bespoke cocktail company and local street food vendors, 'Fresh Food', while Burger and Fringe, housed in the Radisson blue hotel on the City's Royal Mile, offered a range of handmade Scotch beef burgers and a range of desserts. More generally during the Festival much of George Street is temporarily pedestrianised and many of the traditional restaurants along that street construct pop up extensions to their existing premises.

The annual Festival aside the city also hosts a number of pop up hospitality venues though some of these are seasonal. 'Comet and Blitzen', for example, opened as a pop up bar from 19th November 2016 to $4^{\text {th }}$ January 2017 in former bank premises in North West Circus Place in Stockbridge, a mile north of the city centre. This bar offered a range of craft beers and wine and fondue, Christmas themed plates, locally made cakes and Artisan roast coffee. The bar itself had an open fire, was decorated with Christmas trees, had a number of leather armchairs and sofas as well as two large tables and benches and in many ways the atmosphere was reminiscent of an après-ski shack. Discussions with one of the entrepreneurs behind the venture suggested that the bar would not be financially viable outside the festive season and that establishing the bar as a permanent feature would be likely to meet vociferous opposition from local residents. By way of contrast the 'Pitt Street Food Market' in Leith opened as an outdoor, partly canvas covered, pop up food, drink and music venue on Saturdays from $24^{\text {th }}$ September to 17 December. 
Food vendors included 'The Crema Caravan', specializing in desserts, 'The Buffalo Truck' offering fried chicken and chips, 'Barnacles \& Bones', served shellfish and unusual cuts of meat and 'Pizza Geeks' and locally based craft brewers 'Barney's Beer' ran a drinks counter. Pop up food outlets were also a common feature at the weekly Stockbridge Market and the Leith Farmers Market.

More generally customised bars and hotels are also emerging as an embryonic element within the UK's pop up hospitality scene. The Spacial Installations company, supplies pop up pubs in free standing locations. The company's standard two storey pop up public house, which includes a traditional bar area on the ground floor and an enclosed seating area and open air terrace on the first floor, is built around a core of three shipping containers and takes a day to erect and another to dismantle. These pubs can be customised to suit particular occasions and are supplied with floral arrangements, widescreen televisions and sound systems. In 2016, for example, the company supplied pop up pubs for the Goodwood Revival event in West Sussex, for a Barclaycard Promotional event in Hyde Park, the Silverstone Classic motor racing festival and at Blenheim Palace for the BBC's 'Country Matters' television programme. In a similar vein The 'Pop Up Hotel' company supplies what it describes as a 'transient hotel' which offers 'a defragmented hotel that moves and pops up at events and beautiful locations' (Pop Up Hotel Company 2017, webpage). The company provides luxury tented accommodation at major events and festivals, often in rural areas, and the accent is on 'blending romance, luxury and the thrill of camping, our glamping approach gives you the services you would expect at a boutique hotel, in a location that you wouldn't. We want to keep you connected to the environment you're staying in, rather than isolating you from it' (Pop Up Hotel Company, 2017). The Raj Tenthouse Suite, for example, includes 3 or 4 fully furnished bedrooms to sleep up to 8 people, furnished living and dining area, carpeted floor, all bed linen and towels and toiletries, clothes hanging storage, a bathroom with shower, flushing toilet and basin and a front deck with chairs.

\section{Discussion}

Pop up restaurants, bars and hotels are currently a diverse but popular element in the UK's hospitality mix and while their current contribution to that mix may be small a number of issues merit discussion. Pop up restaurants and bars can be seen to generate a 'buzz' and a temporary sense of excitement within existing retail areas and restaurant quarters within towns and cities. More expansively Davis, Coffer and Lyons (2015), the London based estate agents and leisure property consultants which have been involved in a number of pop up ventures, argued that 'there is no denying the huge impact that the trend has had on the way we eat and drink, largely in the capital, but with its influence reaching ever further.' As such they may help to increase footfall to such areas which will in turn not only benefit existing retail outlets and 
hospitality venues but where vacancy rates are high they may also bring a renewed sense of vitality and viability to such centres. Where pop up restaurants and bars are established on vacant industrial land and buildings within cities such ventures may be important in helping to seed ideas about the potential change of use of such land and its redevelopment as part of wider urban regeneration programmes.

While pop up ventures are transient, a pop up restaurant, for example, provides an important opportunity for chefs to present their food to customers and to allow customers to experience new menus and cuisines. In short the pop up concept enables entrepreneurs to market test new ideas and experiences in, an albeit temporary, commercial setting and thus potentially to extend the nature of the service experience within the hospitality industry. While some pop up ventures will inevitably fail and some operators and entrepreneurs may find it operationally and financially more attractive to continue to trade in pop up mode, some have certainly used pop up ventures to market test and refine their ideas prior to opening a permanent restaurant or bar. Nichols (2013), for example, suggested that 'a temporary site allows an operator to trial a concept, raising awareness of the brand and themselves and making a pitch to a potential backer or landlord more credible' and claimed that 'the pop up restaurant is fast becoming the new weapon in securing a permanent site.' In a similar vein Davis Coffer Lyons (2015), argued 'from short events with a focus on brand awareness, to concept trialing, residencies and short term leases, we have worked with our landlord clients and operators, traders and food retailers on a range of situations, securing the first bricks \& mortar homes for a number of exciting operators.' More specifically Davis, Coffer and Lyons (2015) reported that 'Carnaby secured two firsts in providing a permanent home for BBQ concept Pitt Cue Co, following the huge success of its South Bank street truck ...... and steak concept Flat Iron, from its humble beginnings above the Owl \& Pussycat Pub in Shoreditch.' Away from London Leeds Hedonist Drinks, established Leeds' first pop up gin bar in 2015, later moving to it to another temporary location within the city before moving to a permanent location later that year.

More generally the ways in which many pop up hospitality entrepreneurs have harnessed experiential marketing may have broader implications for the hospitality industry and more generally for the service sector of the economy. While many pop up restaurants and bars have been successful in getting customers to experience, and perhaps more importantly, to engage with chefs and other customers, and such successes would seem to have potentially important implications for other players within the hospitality industry. Here rather than largely relying on conventional advertising and marketing techniques the focus would be more on the emotions and memories that customers have of their hospitality experience.

At the same time the creative ability to develop an attractive physical environment and service experience, to effectively transform what in many cases is an empty space in a neglected location, surely highlights the importance of creative and innovative thinking throughout the hospitality 
industry. While the physical and sensory experience is seen to be vitally important innovative and cost effective marketing has also played a key role in determining the success of pop up ventures. Many pop up websites are as, and in many cases, more attractive, functional and user friendly than the websites used by many of the major players within the hospitality industry. Here social currency, essentially the sharing of information which encourages further social encounters, certainly seems to have been a cost effective approach to marketing. However, there seem to be more general problems in measuring the effectiveness of experiential marketing and what has been perceived to be successful on a small scale within a relatively small geographical area may not necessarily prove successful for larger players within the hospitality industry.

The ways in which pop up hospitality ventures have harnessed experiential marketing may also bear fruit elsewhere within the service sector of the economy. Seemingly gloomy predictions at the end of 2016 of general stagnation in the UK retail economy, linked in part to the results of the national referendum decision to leave the European Economic Community, suggests that retailers may well be exploring innovative approaches to their marketing strategies in an attempt to enhance their brand image, attract new and retain existing customers and to increase their market share within what seems likely to be an ever more competitive trading environment. That said experiential stores are not new and Jones et al. (2010: 245) reported that a number of electronic and mobile phone retailers had been developing experience store formats for over a decade to encourage 'customers to form bonds with their brand' and to 'to develop store designs that translate their brand identity from their products and services into the customer experience of a retail environment'. More generally a variety of small pop up shops have emerged as an innovative element in many parts of the world including cities in North America, Western Europe, Russia, Japan, Singapore, Hong Kong, South Africa and Brasil (Jones et al., 2016). A number of luxury brands, for example Chanel and Hermes, have opened pop up stores in major cities as a 'form of brand communication' and to meet 'the growing demands of a clientele eager for new purchase experiences. We show that pop-up luxury stores add new features to the traditional luxury sector: informality, friendliness, lucidity and accessibility in the context of shared emotions' (de Lassus and Friere, 2014: 61). At the same time high vacancy rates in town and city centres in the UK, for example, have encouraged a wide range of entrepreneurs to open pop up shops selling more mainstream merchandise (Jones et al., 2016).

However, the larger retailers have been slow to embrace an experiential approach to marketing and more specifically Jones et al (2010: 247) argued 'developing experience stores as a means of developing brand relationships may prove difficult across the whole of the retail spectrum.' That said Tesco, the UK's largest retailer, temporarily took over an art gallery in the Soho district of London and opened a pop up wine bar. Here the accent was on offering customers what was described as 'a personalised, intimate and immersive experience' which 'is a world away from the supermarket aisles' (Gilliland, 2016). The bar had some 70 different wines, staff were on hand to 
offer advice and customers were encouraged to sign up for wine masterclasses. Other large food retailers within the UK, including Waitrose and Aldi have experimented with similar pop up ventures and John Lewis opened 'The Gardening Society' pop up food and wine bar on the roof of its Oxford Street Store during November and December 2016. Such initiatives reflect the growing links between retailing and hospitality but they also provide opportunities for large retailers to explore ways in which they can harness the power of experiential marketing and develop a greater sense of emotional engagement with customers.

\section{Conclusion}

A wide variety of pop up restaurants and bars have emerged as an innovative element in the hospitality industry within the UK and impacts and benefits can be identified at a number of levels. At the operational level, for example, they provide entrepreneurs and aspirants within the hospitality industry with relatively low cost opportunities to market test their ideas, skills and expertise and potentially to build their brand. Customers have the opportunity to develop relationships with these entrepreneurs, with the food and drink they offer and with other customers often in an innovative environment. More generally at the industry level such pop up ventures have actively embraced experiential marketing and as such they can be seen to offer new approaches to marketing within the hospitality industry, and perhaps, more widely within the service sector of the economy.. Looking to the future if experiential marketing is to play a more significant role within the hospitality industry then the accent seems likely to be on encouraging greater creativity and on harnessing mobile communications technology more effectively, particularly via social media, to enable consumers to enhance a positive association with products, services and experiences. While the current market structure of the pop up hospitality ventures tends to be dominated by small independent entrepreneurs and businesses, the evidence from the retail world suggests that the large players in the hospitality industry may increasing look to introduce pop up features into their offer in an attempt to engage more fully, and eventually more profitably, with their customers. At the academic level while this paper offers a preliminary sketch of the diversity of pop up hospitality ventures within the UK and some initial reflections on the role of experiential marketing within the hospitality industry, it can be seen to provide a platform for future research. Such research might, for example, profitably include/focus on more detailed qualitative empirical investigations of how customers perceive and enjoy the pop up experience and on the importance they attach to engagement with entrepreneurs and fellow customers, on the importance of social media networks in spreading the pop up message and on how entrepreneurs, and more generally marketing agencies, can measure the return on both face to face and social media engagement. 


\section{References}

Atwal G and Williams A (2009) Luxury Brand marketing: The experience is everything. Journal of Brand Management 16: 338-346

Baker M J (2003) The Marketing Book. Oxford: Butterworth-Heinemann.

Barras J (2006) Pop up Republic. New Jersey: John Wiley.

Bilgihan A and Nejad M (2015) Innovation in tourism and hospitality industries. Journal of hospitality and Tourism Technology 6: 196-202

Clammer J (2012) Difference and Modernity. Abingdon: Routledge.

Davis Coffer Lyons. (2015) Development and London Estates Leasing/Pop Ups. Available at: http://bit.ly/2pZ0oAo. [Accessed 23 November 2016].

De Lassus C and Friere NA (2014) Access to the luxury brand myth in pop up stores: A netographic and semiotic analysis. Journal of Retailing and Consumer Services 21: 61-68

Dutta P, Grimmer M, Arora A, Bibyk S, and Culler D (2005) Design of a Wireless Sensor Platform for Detecting Rare, Random and Ephemeral Events. Proceedings of the $4^{\text {th }}$ International symposium on Information Processing in Sensor Networks, Article 70. Available at: http://bit.ly/2pZ7kgy [Accessed 24 April 2017].

Eventbrite. (2015) The Rise of Pop-Up Dining Events and the Experiential Diner. Available at: http://bit.ly/2plsKsi. [Accessed 5 January 2017].

Gilliland N (2016) Tesco explores experiential marketing with pop-up wine bar. Available at: http://bit.ly/2otuUSz. [Accessed 8 January 2017].

Haynes J (2016) Jim Haynes. Available at: http://bit.ly/1o1gwJj [Accessed 5 January 2017].

Hine C (2011) Internet Research and Unobtrusive Methods. University of Surrey Social Research Update 16. Available at: http://bit.ly/1rt9yTH [Accessed 24 April 2017].

Jones P, Comfort D, Clarke-Hill C, and Hillier D (2010) Retail Experience Stores: Experiencing the Brand at First Hand. Marketing Intelligence and Planning 28: 241-248

Jones P, Hillier D, and Comfort D (2017) The two market leaders in ocean cruising and corporate sustainability. International Journal of Contemporary Hospitality Management 29.

Jones P, Comfort D, and Hillier D (2016) Surveying the Pop-Up Scene. Town and Country Planning 85: 533-537

London Pop-ups. (2016) London Pop-ups. Available at: http://bit.ly/1151B1Z [Accessed 5 January 2017].

Myrick R (2016) Pop Up Restaurants Continue to Grow. Available at: http://bit.ly/2plwnym [Accessed 5 January 2017].

Nichols L (2013) Pop up to permanent: The lasting legacy of temporary restaurants. Available at: http://bit.ly/2plu1iP [Accessed 8 January 2017].

Petkus E (2004) Enhancing the application of experiential marketing in the arts. International Journal of Non-Profit and Voluntary Sector Marketing 9: 49-56

Pop Up Hotel Company. (2017) Experience A Stay. Available at: http://bit.ly/11ZDKl5 [Accessed 12 January 2017].

Potts A (2007) The Enduring Ephemeral. Tate Papers 8. Available at: http://bit.ly/2o Yu1T1 [Accessed 24 April 2017].

Schmitt B (1999) Experiential Marketing. Journal of Marketing Management 15: 5367 
The Department for Communities and Local Government. (2013) New opportunities for sustainable growth and development through the reuse of existing building. Available at: http://bit.ly/2obJodI [Accessed 23 November 2016].

This is Edinburgh. (2016) 10 Brilliant Edinburgh Festival Pop-Ups for 2016. Available at: http://bit.ly/2plJzTE [Accessed 5 January 2017].

WalesOnline. (2015) 11 Pop ups that are transforming Cardiff's food scene. Available at: http:// www.walesonline.co.uk/whats-on/food-drink-news/pop-up-cardifffood-restaura nt-8901337 [Accessed 6 January 2017].

Yuan $\mathrm{YH}$ and $\mathrm{Wu}$ CK (2008) Relationships among experiential marketing, experiential value, and customer satisfaction. Journal of Tourism and Hospitality Research 32: 387-410 
